\title{
Erratum to: Role of the Conserved Thr399 and Thr417 Residues of Bacillus licheniformis $\gamma$-Glutamyltranspeptidase as Evaluated by Mutational Analysis
}

\author{
Rui-Cin Lyu $\cdot$ Hui-Yu Hu $\cdot$ Lih-Ying Kuo $\cdot$ \\ Huei-Fen Lo $\cdot$ Ping-Lin Ong · Hui-Ping Chang • \\ Long-Liu Lin
}

Published online: 6 October 2009

(C) Springer Science+Business Media, LLC 2009

Erratum to: Curr Microbiol (2009) 59:101-106

DOI 10.1007/s00284-009-9403-1

The name of one of the authors of this article (Rui-Cin Lyu) was inadvertently misspelled in the online and print versions published previously. The author's name is presented correctly here.

The online version of the original article can be found under doi:10.1007/s00284-009-9403-1.

R.-C. Lyu · H.-P. Chang · L.-L. Lin ( $ه)$

Department of Applied Chemistry, National Chiayi University, 300 University Road, Chiayi 600, Taiwan

e-mail: 1lin@mail.ncyu.edu.tw

H.-Y. Hu · L.-Y. Kuo · H.-F. Lo

Department of Food and Nutrition, Hungkuang University,

Shalu, Taichung, Taiwan

P.-L. Ong

Department of Biochemical Science and Technology, National

Chiayi University, 300 University Road, Chiayi 600, Taiwan 